\title{
Measuring change in longitudinal research on pragmatic competence: A multinomial logistic model
}

\author{
Anna Szczepaniak-Kozak ${ }^{1}$, Ewa Bakinowska ${ }^{2}$, Katerina Strani ${ }^{3}$ \\ ${ }^{1}$ Institute of Applied Linguistics, Adam Mickiewicz University, al. Niepodległości 4, \\ 61-874 Poznań, Poland, annkozak@amu.edu.pl \\ ${ }^{2}$ Institute of Mathematics, Poznań University of Technology, Piotrowo 3A, 60-965 Poznań, \\ Poland, ewa.bakinowska@put.poznan.pl \\ ${ }^{3}$ Department of Languages and Intercultural Studies, Heriot-Watt University, Edinburgh, \\ Riccarton, Edinburgh EH14 4AS, Great Britain, A.Strani@hw.ac.uk
}

\section{SUMMARY}

\begin{abstract}
This paper focuses on pragmatic competence development in second or foreign language learners. In particular, it attempts to fill the significant research gap in measuring change in pragmatic competence and capturing pragmalinguistic and sociopragmatic development over time. The paper proposes an innovative approach by applying a logistic model with multinomial distribution for measuring change in InterLanguage Pragmatics Research (ILP). Applied in the field of pragmatics, this statistical tool offers a comprehensive and flexible approach to modelling relations between independent and dependent variables in ILP research. The model is tested in a longitudinal study of Polish undergraduate students learning English, and specifically in the way they formulate requests by means of requestive directness strategies. The paper concludes that, regardless of time elapsing, the factors $P$ (power distance) and $D$ (social distance) have a highly significant influence on the use of requestive directness strategies by Poles learning EFL. Furthermore, the analysis indicates that the pragmatic output of Poles learning EFL is dependent on one more independent variable: the estimation of future social distance $(F)$.
\end{abstract}

Key words: pragmatic competence, interlanguage pragmatics, longitudinal research, multinomial logistic model, EFL

\section{Introduction}

Since the 1980s there has been ample theoretical and empirical research on pragmatics across languages. Such research has included how "different languages and cultures compare and contrast pragmatically" (O'Keeffe et al., 2011: 101), as well as how learners of a second/foreign language acquire pragmatics in a target language. However, researchers' preference for contrastive 
studies of second/foreign language use continue to set the tone in this domain. To illustrate this, Taguchi (2010) found 21 longitudinal studies that were published prior to 2008, while a similar synthesis study conducted by Li (2016) identified only 26 published papers. Studies enabling a deeper and more nuanced understanding of the learning of the pragmatics of a foreign language continue to be less common than those capturing pragmatics at one point in time (cf. Jaworski, 1994; Lewandowska-Tomaszczyk, 1989; Martínez-Flor and Usó-Juan, 2006; Ghavamnia et al., 2011; Gomez-Laich, 2016). Consequently, there is an urgent need for research that focuses on pragmatic competence development in second or foreign language learners. Recent publications which try to narrow this gap in research, and which Li (2016) does not mention, include Glaser (2014) on dispreferred speech acts, and Szczepaniak-Kozak (2018) with reference to requests.

This paucity of research is perhaps caused by the fact that there are even fewer publications on how to measure change in pragmatic competence (henceforth PC), that is, how to capture pragmalinguistic and/or sociopragmatic development over time, except for Matsumura (2001). Ogiermann and Saßenroth (2012: 370) are of the same opinion: "Most of the literature on statistics that pragmaticians refer to has been written for other disciplines, such as psychology and sociology." This paper aims to fill these research gaps and contribute to a theoretical and empirical discussion on the study of ILP. More specifically, it suggests that a multinomial logistic model can be used for analysing pragmatic output collected over an extended period of time from the same group of participants (repeated-measures design). This statistical tool offers a comprehensive and flexible approach to modelling relations between independent and dependent variables in ILP research.

\section{Background: Analysis tools currently in use in ILP research}

Previous studies devoted to investigating changes in PC in second/foreign language learners rely on quantitative, qualitative or mixed methods for analysing collected pragmatic output. Table 1 summarises the statistical methodologies applied to measure change in such research, as provided by recent reports 
(published since 2001). The selection of the papers is not random, but purposeful - the list is intended to show which methods have been used in the research domain. The table provides a chronological summary of quantitative and/or mixed methods. It does not include purely qualitative analyses, because these are not the focus of this paper.

The table below demonstrates that there are basically three types of statistical tools which are used to calculate the scale of change in longitudinal research on pragmatics: descriptive statistics, the $t$-test, and statistical analysis of variance (ANOVA). The $t$-test is used to test differences between two groups, while ANOVA is employed when more than two groups are compared (Ogiermann and Saßenroth, 2012: 382-383). The most common indicators of PC are frequencies of use of certain strategies and/or semantic formulas, for example, address forms (Barron, 2006), requestive forms (Bataller, 2010) or requestive modifications (Kim and Taguchi, 2015). Additionally, the majority of the research relies on multi-group comparisons by means of statistical analysis of variance (ANOVA), which is useful in answering the question whether the "observed variables representing the groups are statistically significant" (Matsumura, 2001: 650). Although the $t$-test and ANOVA are particularly useful when we want to "test a group's performance on several occasions", including progress over time, what makes them less suitable for pragmatics data is that "these tests have been designed for metric rather than nominal data as they are based on comparisons of means" and provide reliable results with the assumption of the normality of distribution (Ogiermann and Saßenroth, 2012: 383). Where the data is skewed (Taguchi, 2007 and 2008), some researchers apply logarithmic transformations in order to obtain a normal distribution of data. However, we agree with Matsumura (2001: 650, 652) that "looking solely at the means of observed variables may be problematic, because they are functions of other parameters in the model." Finally, ANOVA can be applied in the standard linear model when the data fulfils the normality criterion, or the residuals are normally distributed. In our case, the data is not characterised by normality, which excludes the possibility of applying group comparison by means of ANOVA. 
Table 1. How the effect of time on gains in PC is measured: A chronological overview

\begin{tabular}{|c|c|}
\hline Research (participants, measurement instruments) & $\begin{array}{l}\text { How the effect of time on gains in } \\
\text { PC was measured }\end{array}$ \\
\hline \multicolumn{2}{|l|}{ Matsumura (2001) [Qualitative-quantitative] } \\
\hline $\begin{array}{l}93 \text { university-level students in an } 8 \text {-month abroad study } \\
\text { in Canada in comparison to } 132 \text { students of EFL in } \\
\text { Japan; multiple-choice questionnaire used three times to } \\
\text { assess changes in their sociocultural perceptions of } \\
\text { social status and the impact of the assumed changes on } \\
\text { the way the participants offer advice in English }\end{array}$ & $\begin{array}{l}\text { structural equation modelling } \\
\text { (SEM) used to measure the } \\
\text { approximation of the students' } \\
\text { preferences for advice type to } \\
\text { native speaker (NS) preferences }\end{array}$ \\
\hline \multicolumn{2}{|l|}{ Taguchi (2007) [Qualitative-quantitative] } \\
\hline $\begin{array}{l}92 \text { Japanese college students of English participated } \\
\text { twice (over } 7 \text { weeks) in a computerised listening task to } \\
\text { measure their ability to understand two types of implied } \\
\text { meaning in dialogues; this ability was measured as the } \\
\text { accuracy (score in the test) and speed (average time } \\
\text { taken to answer each test item) }\end{array}$ & $\begin{array}{l}\text { development of accuracy and } \\
\text { speed of comprehension analysed } \\
\text { by means of two paired-sample } t \text { - } \\
\text { tests; because the raw data did not } \\
\text { meet the assumption of normality, } \\
\text { linearity and homoscedasticity } \\
\text { (positive skewness), logarithmic } \\
\text { transformation was performed }\end{array}$ \\
\hline \multicolumn{2}{|l|}{ Taguchi (2008) [Qualitative-quantitative] } \\
\hline $\begin{array}{l}\text { 44 Japanese college students in the USA (study-abroad; } \\
\text { intensive language course) observed in order to } \\
\text { investigate their gains in accuracy and speed of } \\
\text { comprehension of implied meaning; the accuracy was } \\
\text { determined as the test score in a pragmatic listening test, } \\
\text { and the speed as the average response time taken to } \\
\text { answer the test items (measured } 3 \text { times over } 4 \text { months) }\end{array}$ & $\begin{array}{l}\text { ANOVA was used; because the } \\
\text { distribution of the time data was } \\
\text { found to be abnormal, logarithmic } \\
\text { transformation was performed to } \\
\text { meet the assumption of normality, } \\
\text { linearity, and homoscedasticity; } \\
\text { the accuracy scores were } \\
\text { measured by means of the mean, } \\
S D \text {, and the minimum and } \\
\text { maximum of the test score }\end{array}$ \\
\hline \multicolumn{2}{|l|}{ Takimoto (2008) [Qualitative-quantitative] } \\
\hline $\begin{array}{l}60 \text { adult Japanese EFL learners at the intermediate level } \\
\text { participated over a period of } 6 \text { weeks in purposefully } \\
\text { designed instruction (inductive, deductive); a discourse } \\
\text { completion task (DCT), a role-play (RP) test, a listening } \\
\text { test and an acceptability judgment test were used to } \\
\text { measure the extent of the change in the study } \\
\text { participants' use of lexical/phrasal downgraders and } \\
\text { syntactic downgraders in English to perform complex } \\
\text { requests; DCT and RP test output was rated for } \\
\text { appropriateness on a 5-point scale }\end{array}$ & $\begin{array}{l}\text { one-way ANOVA, used to } \\
\text { indicate whether there are } \\
\text { statistically significant differences } \\
\text { between the output collected from } \\
\text { treatment groups and the control } \\
\text { group in the tests applied; a post } \\
\text { hoc Scheffé test was also applied } \\
\text { to the participants' scores in the } \\
\text { listening test }\end{array}$ \\
\hline \multicolumn{2}{|l|}{ Taguchi (2011) [Qualitative-mixed methods] } \\
\hline $\begin{array}{l}\text { an oral DCT was used to measure the increase in } \\
\text { appropriateness and speech rate (of requests and } \\
\text { opinions) in } 48 \text { advanced Japanese college students } \\
\text { learning English in an immersion environment over a } \\
\text { period of one academic year }\end{array}$ & $\begin{array}{l}\text { repeated-measures ANOVA was } \\
\text { applied to analyse the effect of } \\
\text { time on gains for low- and high- } \\
\text { imposition speech acts }\end{array}$ \\
\hline \multicolumn{2}{|l|}{ Li (2014) [Qualitative-quantitative] } \\
\hline $\begin{array}{l}\text { a Computerised Oral Discourse Completion test } \\
\text { (CODCT) distributed to } 31 \text { Americans studying Chinese } \\
\text { in China at the beginning and end of their stay in China, }\end{array}$ & $\begin{array}{l}3 \text { separate } 2 \text { (group) } 2 \text { (time) } \\
\text { repeated ANOVAs (paired } \\
\text { sample } t \text {-tests) were conducted }\end{array}$ \\
\hline
\end{tabular}




\begin{tabular}{l} 
lasting in total 15 weeks. CODCT included eight \\
request-making scenarios and a few filler items; the \\
responses were analysed in terms of their \\
appropriateness (on a 5-point scale) and the speed of the \\
participants' performance \\
Alcón-Soler (2015) [Qualitative-mixed methods] \\
\hline 60 Spanish teenage learners' ability to mitigate requests \\
in e-mail communication with their English language \\
teachers during their one academic year stay in England \\
was investigated to decide to what extent pragmatic \\
instruction and length of study influence learners' so- \\
directed ability; the test was administered four times \\
over the period of the study
\end{tabular}

over the period of the study for appropriateness rating, planning time and speech rate; a post hoc analysis compared the mean numbers of various elements constituting requests

descriptive statistics was used to trace changes in the frequency of internal mitigation; $t$-test was applied to check if there are differences in all types of request modifiers between the control and experimental group pertaining to requestive mitigation; a split-plot ANOVA with repeated measures was used to decide whether the instructional effect was sustained over the period of the study

Kim and Taguchi (2015) [Qualitative-quantitative] 73 adolescent Korean junior high school students of EFL were observed over a period of six weeks; DCT was applied to examine whether there were group differences in requestive head act scores and in the frequency of their modifications

the frequencies of request
modifications were examined;
because the data collected did not
confirm a normal distribution,
Mann-Whitney $U$-tests were run
to examine whether there were
group differences in the head act
scores and in the frequency of
request modifications
request modifications

Takahashi (2015) [Qualitative-mixed methods] 154 Japanese EFL learners were involved in a study which examined the effects of motivation and linguistic proficiency on the awareness of bi-clausal request forms and their learning in the context of implicit pedagogical intervention; the concept of awareness was operationalised as the summation of learners' "interest" in the target forms and their "detection capacity" of these forms; data relevant to the awareness session was obtained through video dictation tasks, whereas the learners' pragmalinguistic development was assessed through oral discourse completion tasks in pre- and post-test sessions

Schenker (2016) [Qualitative-mixed methods]

e-mail correspondence was collected from 19 American college students of German as a foreign language over a period of 12 weeks; the mean length of a T-unit was calculated in order to measure increase in global text complexity; the average subordination amount per Tunit was examined in order to measure complexity via subordination, and sub-clausal complexity by means of changes in syntactic complexity in the L2 learners' emails

\author{
cluster analysis on two motivation \\ subscales and listening \\ proficiency was used; one-way \\ repeated measures ANOVA was \\ run to examine whether learner \\ profiles impact awareness and \\ pragmatic learning
}


Matsumura (2001) attempted to solve this methodological problem in his investigation of groups of Japanese learners of English as a second language (ESL) and English as a foreign language (EFL). Hypothesised changes in these learners' pragmatic performance were measured with a multi-group latent means model. The model relied in calculations on the averages of latent variables deriving "not only from the means of observed variables but also from the structured coefficients in the model" (Matsumura, 2001: 652). Despite the undeniable merits of Matsumura's model, it does not allow the estimation of the unknown probability of use.

Against this backdrop, we put forward another approach to measuring change in ILP, which, to the best of our knowledge, has not been used in ILP research so far.

\section{Our proposal: Logistic model with multinomial distribution}

Despite the usefulness of the data analysis procedures known and widely applied in ILP (see Table 1), there is a great need for a statistical method that could allow for the abnormality of the pragmatic output which is collected in longitudinal or pseudo-longitudinal research. In order not to conduct logarithmic transformations of data which is assumed to be skewed, we suggest that a logistic model with multinomial distribution (McCullagh and Nelder, 1989) can be applied for this purpose. This would allow not only measurement of the scale of change in pragmatic output and/or in comprehension on raw data, but also estimation of the unknown probability of use (that is, the success of a particular category as dependent on the values of independent variables, which in our case are parameters of linguistic context). In what follows, we show how the model was developed and later put it to the test in an example study.

The standard linear model can be written in matrix form as:

$$
\boldsymbol{\mu}=\mathbf{X} \boldsymbol{\beta},
$$

where $\boldsymbol{\mu}$ is the vector of expected values of observations $E(\mathbf{y})=\boldsymbol{\mu}_{(n \times 1)}, \mathbf{y}^{T}=$ $\left(y_{1}, y_{2}, \ldots, y_{n}\right), \mathbf{x}_{(n \times(p+1))}$ is the known matrix of covariates, and $\boldsymbol{\beta}_{((p+1) \times 1)}$ is 
the vector of unknown parameters. Since the parameters in vector $\boldsymbol{\beta}^{T}=$ $\left(\beta_{0}, \beta_{1}, \ldots, \beta_{p}\right)$ can assume all real values $(-\infty,+\infty)$, this model is adequate for describing random variables with normal distribution. These may be continuous variables used to describe traits such as weight, length, temperature, average/mean test scores or average grade. However, the case is different when the collected observations are nominal, that is, capable of being divided into categories. Then the standard linear model is insufficient. In particular, the standard model cannot be applied to statistical analysis of so-called discrete random variables: 1) data which assumes natural values: $0,1,2, \ldots$, e.g., test scores expressed in points, or 2) observed probabilities, the so-called frequencies, which assume values from 0 to 1 , e.g., percentage of the total score.

Some types of data capable of being divided into categories can be ordered following a scale from one extreme to the other. In such cases, units/samples/responses elicited or observed (in pragmatics, for example, realisations of a given head act, types of mitigation) are classified according to an ordinal scale into separate categories. Subsequently, frequencies of individual categories are observed and recorded. The so-called ordinal logistic regression model is adequate to describe and analyse such data. The data which will serve as the basis for an example presentation of how our model works constitute a corpus which can be divided into twelve separate ordinal categories. Therefore, the above-mentioned logistic model can be used for analysis, and the necessary regression model can be written in the following form, suited to the particular nature of our data:

$$
\log \frac{\gamma_{j}}{1-\gamma_{j}}=\theta_{j}+\beta_{1} x_{1}+\beta_{2} x_{2}+\ldots+\beta_{p} x_{p}, \quad j=1,2, \ldots, k-1,
$$

where $\log (\cdot)$ denotes natural logarithm, $\theta_{j}$ is the border (cut-off point) of the $j$-th category, $k$ is the number of categories, $x_{1}, x_{2}, \ldots, x_{p}$ are independent variables, $\beta_{1}, \beta_{2}, \ldots, \beta_{p}$ are the unknown regression parameters, and $\gamma_{j}$ is the $j$-th cumulative probability

$$
\gamma_{j}=p_{1}+p_{2}+\ldots+p_{j}, \quad j=1,2, \ldots, k-1 .
$$


In order to draw conclusions concerning the classified units, the data is modelled with the use of a multinomial distribution, which is determined by the probabilities $p_{j}, j=1,2, \ldots, k$, summing to one, $\sum_{j=1}^{k} p_{j}=1$, and the fixed number of units $m$ ( $m$ stands for the participants' responses which are classified into $k$ separate categories, $k=12$ in our case; $p_{j}$ is the probability of the success of the $j$-th category).

In the example application of the model, the analysis is aimed at estimating the unknown probabilities in model (1), based on the data elicited in research conducted to observe gains in PC among Polish learners of EFL (discussed in detail later). Therefore, the set of equations (1) can be written in matrix form as:

$$
\mathbf{C}^{\mathrm{T}} \log (\mathbf{L p})=\mathbf{X} \boldsymbol{\beta},
$$

where $\mathbf{C}_{(n \times l)}^{T}$ is the matrix of contrasts, $\mathbf{L}_{(l \times k)}$ is the fixed binary matrix (which forms selected sums of elements of the probability vector $\mathbf{p}_{(k \times 1)}$ in the product $\mathbf{L} \mathbf{p})$, and $\boldsymbol{\beta}^{T}=\left(\boldsymbol{\theta}^{T}, \beta_{1}, \beta_{2}, \ldots, \beta_{p}\right)$ is the vector of parameters, where $\boldsymbol{\theta}_{((k-1) \times 1)}$ denotes the vector of cut-off points (borders between successive categories).

The estimates of unknown parameters in model (2) can be obtained using the maximum likelihood method. The main difficulty is solving the maximum likelihood equation, which is non-linear. The solution can be provided by iterative methods (McCullagh and Nelder, 1989: 42; McCulloch and Searle, 2001: 105). One of these methods is known as the Fisher scoring method (FS) (cf. McCulloch and Searle, 2001: 143; Bakinowska, 2004). To test the hypothesis

$$
H_{0}: \boldsymbol{\beta}=\boldsymbol{\beta}_{*},
$$

the Wald statistic can be used. The Wald test statistic has the following form:

$$
\left(\widehat{\boldsymbol{\beta}}-\boldsymbol{\beta}_{*}\right)^{T} \boldsymbol{F}(\widehat{\boldsymbol{\beta}})\left(\widehat{\boldsymbol{\beta}}-\boldsymbol{\beta}_{*}\right)
$$

and has approximate $\chi_{p}^{2}$ distribution ( $p$ being the order of $\boldsymbol{\beta}_{*}$ ), where $\widehat{\boldsymbol{\beta}}$ is an estimate of $\boldsymbol{\beta}$, and $\boldsymbol{F}(\widehat{\boldsymbol{\beta}})$ is the information matrix of $\widehat{\boldsymbol{\beta}}$ (see Agresti, 1984: 230; McCulloch and Searle, 2001: 24). This model offers two definite advantages. It allows the estimation of unknown probabilities as well as computations, without relying on averages, but on raw or untransformed data. 
In the next section, we will demonstrate that the multinomial logistic model can provide statistical evidence on changes in the PC of EFL learners. The details of the research design, including the testing procedure and its findings, are presented first.

\section{Longitudinal study: An example}

We investigate the usefulness of the above-presented model for measuring the scale of change in PC using the data collected in a mixed-methods study on ILP among Polish EFL learners, conducted by Szczepaniak-Kozak (2018). This research included a longitudinal observation of a group of students learning EFL. PC was operationalised in this study as the formulation of requests. The data collected was analysed with respect to the independent variables represented in the measurement instrument as captured over an extended period of time.

\subsection{Participants in the study}

The participants in the longitudinal study were undergraduate students of English at a university in Western Poland, who entered university at the same time, thus constituting a cohort. At the time of entry, their average age was 19 and their average time of EFL learning was 7.70 years $(\mathrm{M}=4, \mathrm{SD}=3.321$, minimum $=3$, maximum $=14$; age of outset was treated as an individual variable). Their starting proficiency level was at least B2. They entered university on the basis of their score obtained in the state high school matriculation exam called Matura. This exam is given in the same form to all high school graduates, so the scores of such an exam are comparable, which strengthens the reliability of the research sampling procedure. (For lack of space, we do not include more information on the participants' socio-educational background. It is discussed in Szczepaniak-Kozak (2018: 216-219).)

Initially, at the first data collection point, the cohort comprised 50 participants. In the second year, this number was reduced to 39 and then to 37 in the final year due to student dropout. Despite this decrease in the number of study participants, there has not been a larger cohort of language learners whose ILP 
was traced over a longer period of time, to the best of our knowledge and until September 2018. In particular, there were no longitudinal investigations of interlanguage pragmatics that included larger groups observed for more than three years.

On average, the participants received nine hours a week of English language instruction throughout the period of their studies as preparation for the profession of translator or teacher. During that time, the cohort was exposed to pragmatic instruction (Decoo's [1996] A-D modalities) as part of their regular linguistic training (details in Szczepaniak-Kozak, 2018: 211-215). It was expected that due to participation in moderately interventional pragmatic instruction, their pragmatic output, operationalised as the rendering of requests, would indicate gains in their skilfulness to reflect the sociopragmatic variables (which are widely recognised in ILP research) by means of requestive directness and (internal/external) mitigation devices (see Szczepaniak-Kozak, 2018).

\subsection{Data collection points, measurement instrument and independent variables}

The students' PC was tested three times (three data collection points, DCPs) over the period of three academic years by means of a discourse completion task (DCT). The first DCP took place in October 2012 (henceforth FDCP), the second DCP (mid-testing point) in May 2014 (henceforth SDCP), and the third and final DCP in May 2015 (henceforth TDCP). In total, the participants were observed for 32 months.

The DCT was of the open-response format. It included ten requestive scenarios adapted from Liu $(2006$; 2007) with permission (cf. Table 2 below).

Liu's questionnaire (2006: 195-196; 2007: 395-404) was meticulously developed. He applied pilot studies and interim testing procedures to strengthen the reliability and validity, especially content and criterion-related validity, of his DCT (Liu, 2006: 83-97; 2007: 393-409). Some selected statistical characteristics of his test are as follows (for a more detailed description see Liu, 2006: 107-152): 
Table 2. The requestive scenarios and their labels used in the present study (developed from Liu, 2006: 195-196 and 2007: 395-404)

\begin{tabular}{|c|c|c|}
\hline No. & Label & Acronym - Wording of the scenario \\
\hline 1 & $\begin{array}{l}\text { Loud } \\
\text { music }\end{array}$ & $\begin{array}{l}\text { LM - You are trying to study in your room and you hear loud music } \\
\text { coming from another student's room down the hall. You don't know the } \\
\text { student, but you decide to ask him to turn the music down. }\end{array}$ \\
\hline 2 & $\begin{array}{l}\text { Teacher } \\
\text { repeat }\end{array}$ & $\begin{array}{l}\text { TR - You are now discussing your assignment with your teacher. Your } \\
\text { teacher speaks very fast. You do not follow what he is saying, so you } \\
\text { want to ask your teacher to say it again. }\end{array}$ \\
\hline 3 & Cell phone & $\begin{array}{l}\mathrm{CP}-\text { You are a teacher. In class, the mobile phone of one of your } \\
\text { students rings. You ask your student to turn off his mobile phone. }\end{array}$ \\
\hline 4 & $\begin{array}{l}\text { Blocking } \\
\text { the view }\end{array}$ & $\begin{array}{l}\text { BV - You are watching a basketball game. A student you don't know } \\
\text { comes and stands just in front of you blocking your view. You want to } \\
\text { ask the student not to block your view. }\end{array}$ \\
\hline 5 & $\begin{array}{l}\text { Interview } \\
\text { reschedule }\end{array}$ & $\begin{array}{l}\text { IR - You are applying for a new job in a small company and want to } \\
\text { make an appointment for an interview. You know the manager is very } \\
\text { busy and only schedules interviews in the afternoon from one to four } \\
\text { o'clock on Wednesday. However, you have to take the final-term exam } \\
\text { this Wednesday. You want to schedule an interview on Thursday. }\end{array}$ \\
\hline 6 & $\begin{array}{l}\text { Longer } \\
\text { working } \\
\text { hours }\end{array}$ & $\begin{array}{l}\text { LWH - You are the owner of a bookstore. Your shop clerk has worked } \\
\text { for a year, and you have gotten to know him/her quite well. It is the } \\
\text { beginning of the semester, and you are very busy selling and refunding } \\
\text { textbooks all day. Today you have a plan to extend business hours by an } \\
\text { hour, though you know the clerk has worked long hours in the past few } \\
\text { days. You ask the clerk to stay after store hours. }\end{array}$ \\
\hline 7 & $\begin{array}{l}\text { Test } \\
\text { preparation }\end{array}$ & $\begin{array}{l}\text { TP - For the first time this semester, you are taking a descriptive } \\
\text { grammar course. You have had a hard time following lectures and } \\
\text { understanding the textbook. A test is scheduled to be held next week. } \\
\text { You notice that one student sitting next to you seems to have a good } \\
\text { background knowledge of descriptive grammar, and is doing well. Since } \\
\text { it is the beginning of the semester, you do not know him/her yet. You } \\
\text { want to ask him/her to study together for the upcoming test. }\end{array}$ \\
\hline 8 & $\begin{array}{l}\text { Borrowing } \\
\text { computer }\end{array}$ & $\begin{array}{l}\text { BC - Something is wrong with your computer, but you have to finish } \\
\text { some homework which is due tomorrow. Your roommate has a } \\
\text { computer, but he is also writing a course paper on his computer. His } \\
\text { homework is due the day after tomorrow. You want to ask him to stop } \\
\text { his work and let you use his computer to finish your homework first. }\end{array}$ \\
\hline 9 & $\begin{array}{l}\text { President } \\
\text { interview }\end{array}$ & $\begin{array}{l}\text { PI - You are writing your graduate thesis and need to interview the } \\
\text { president of your university. The president was your teacher and you } \\
\text { know him quite well. You know the president is very busy and has a very } \\
\text { tight schedule. You still want to ask the president to spare one or two } \\
\text { hours for your interview. }\end{array}$ \\
\hline 10 & Note paper & $\begin{array}{l}\text { NP - You are the manager of a company. You are in a meeting with the } \\
\text { other members of your company. You need to write some notes, but } \\
\text { realise you do not have any paper. You turn to the person sitting next to } \\
\text { you. You know the person very well. }\end{array}$ \\
\hline
\end{tabular}


- distributed skewness $(-0.41)$ and kurtosis $(0.51)$ values for the test scores indicated normal distribution (Liu, 2006: 107);

- the internal reliability estimate was calculated at an acceptable 0.9021 (Liu, 2006: 108);

- internal consistency reliability measured by Cronbach alpha equalled 0.95 (Liu, 2006: 108);

- inter-rater reliability computed by means of the Spearman-Brown prophecy formula was 0.903 (Liu, 2006: 108).

The scenarios in the written questionnaire differ in terms of independent variable configurations, and thus satisfy the content validity criterion. In this sense, each scenario evokes a different set of sociopragmatic features. In the analysis presented in Section 5, we assume that these variables are not dependent on each other. Additionally, the independent variables which appear in the scenarios are widely accepted not only as culturally sensitive, especially their metapragmatic evaluation, but also as ones that "subsume all other variables and play a principled role in speech-act behaviour", thus forming vital areas in national pedagogical context (Hudson, 2001: 284). The independent sociopragmatic variables that appear in the DCT are presented below (cf. Brown and Levinson, 1987; Fraser, 1990; Thomas, 1995; Hudson et al., 1995; Hudson, 2001). For statistical analysis, in each variable three levels/degrees were differentiated to show scalar variance/variance in the scale, and these levels were coded into digits ranging from 1 to 3 each. The variables are:

- $\quad P$ - power distance, that is, the degree of the speaker's dominance/power with respect to the hearer, which results from the participants' role relationship, i.e., whether the speaker is higher than the hearer in the organisational hierarchy or other socially binding constellation. $P$ is very often expressed by means of relative rank, position or title, e.g., policeman and a speeding driver. The possible constellations and their values are: $1-\mathrm{S}$ (peaker) lower than $\mathrm{H}$ (earer); $2-\mathrm{S}$ and $\mathrm{H}$ equals; 3 - $\mathrm{S}$ higher than $\mathrm{H}$;

- $\quad D$ - social distance, which stands for the familiarity, affiliation and solidarity between $\mathrm{S}$ and $\mathrm{H}$, represented by means of in-group and out-group membership: 1 - strangers; 2 - acquaintances; 3 - friends/family; 
- $I$ - the degree of requestive imposition, that is, how difficult rendering the request is for $\mathrm{H}$ in terms of the expenditure of information, goods, services or energy: 1 - a trivial request (not difficult to perform); 2 - a mild imposition; 3 - a considerable imposition (difficult to perform);

- $R$ - the speaker's right, that is, the extent to which $\mathrm{S}$ has the right to render the request: 1 - small; 2 - moderate; 3 - considerable;

- $O$ - the hearer's obligation, that is, the degree of H's obligation to carry out the request: 1 - low/voluntary; 2 - moderate/customary; 3 - high/obligatory. In the majority of ILP or cross-pragmatic studies, $R$ and $O$ are not included, and thus this study is one of the very few that interpret the data taking these into account. They depend not only on the particular context of interaction but also on whether a particular service belongs to a certain social or, more often, professional role (Thomas, 1995: 131). Furthermore, these variables are often analysed jointly. In our study, they were treated as distinct variables, initially because it was difficult to express them in one record for quantitative analysis. This was apparently a crucial decision, because $O$ turned out to be a significant correlate of requestive directness in the interlanguage data collected from Polish EFL learners, whereas $R$ did not.

Table 3 presents the DCT requestive situations, taking into account the sociocultural independent variables discussed above $(P, D, I, R$ and $O)$, together with values which represent their strength. It is noteworthy that Scenarios 1 and 4 display the same values of the independent variables. One could expect the pragmalinguistic realisations of the requestive forms elicited by them to be similar. However, as the analysis of the data in Szczepaniak-Kozak (2018: 262, 370 ) indicates, this is not so. She suggests that there is one more independent variable which can account for the differences between pragmalinguistic realisations in these two scenarios: the 'estimation of future social distance' $(F)$. $F$ is a measure of the speaker's subjective evaluation of the chances of striking up a longer social interaction with the hearer. Szczepaniak-Kozak (2018: 278) proposes that this variable could be measured on a three-point scale: 3 - the interlocutors are not strangers, 2 - the interlocutors could become friends, 1 - the interlocutors could not become friends. The multinomial logistic model presented 
in this paper proved sensitive to this variable as well, which means that it enables the gathering of evidence of unknown parameters.

Table 3. Distribution of independent variables and their values in the DCT used in the cohort study

\begin{tabular}{|c|c|c|c|c|c|c|c|c|c|c|}
\hline \multirow{3}{*}{ Independent variable } & \multicolumn{10}{|c|}{ Scenario number and independent variable value } \\
\hline & 1 & 2 & 3 & 4 & 5 & 6 & 7 & 8 & 9 & 10 \\
\hline & $\mathrm{LM}$ & TR & $\mathrm{CP}$ & BV & IR & LWH & $\mathrm{TP}$ & $\mathrm{BC}$ & PI & NP \\
\hline Power distance $(P)$ & 2 & 1 & 3 & 2 & 1 & 3 & 2 & 2 & 1 & 3 \\
\hline Social distance $(D)$ & 1 & 2 & 2 & 1 & 1 & 3 & 1 & 3 & 2 & 3 \\
\hline Imposition $(I)$ & 2 & 1 & 2 & 2 & 3 & 3 & 2 & 3 & 3 & 1 \\
\hline Speaker's right $(R)$ & 2 & 3 & 3 & 2 & 1 & 3 & 1 & 2 & 1 & 2 \\
\hline Hearer's obligation $(O)$ & 2 & 3 & 3 & 2 & 1 & 2 & 1 & 2 & 1 & 2 \\
\hline $\begin{array}{l}\text { Estimation of future } \\
\text { social distance }(\mathrm{F})\end{array}$ & 2 & 3 & 3 & 1 & 2 & 3 & 2 & 3 & 3 & 3 \\
\hline \multicolumn{11}{|c|}{$\begin{array}{l}\text { Legend: Power distance }(P): 1-\text { the speaker is of a lower status than the hearer; } 2-\text { the speaker and the hearer } \\
\text { are of the same status, } 3 \text { - the speaker has a higher status than the hearer; Social distance }(D): 1-\text { the speaker } \\
\text { and the hearer are strangers; } 2 \text { - they are familiars; } 3 \text {-they are close or intimate; Imposition }(I): 1 \text { - the } \\
\text { requested favour is trivial/low; } 2 \text { - the requested favour is a mild imposition; } 3 \text { - the requested favour is a } \\
\text { considerable imposition; Speaker's right to render the request }(R): 1-\text { low; } 2 \text { - moderate; } 3 \text { - } \\
\text { high/considerable; Hearer's obligation to satisfy the request }(O): 1 \text { - it is voluntary; } 2 \text { - it is customary; } 3 \text { - it is } \\
\text { obligatory. 'Estimation of future social distance' }(F): 1-\text { the interlocutors could not become friends; } 2 \text { - the } \\
\text { interlocutors could become friends; } 3 \text { - the interlocutors are not strangers. }\end{array}$} \\
\hline
\end{tabular}

\subsection{Data collected and analysis matrix}

Overall, 1,248 requests were collected over the entire period of study: 495 at FDCP, 386 at SDCP, and 367 at TDCP. The requests were transcribed and coded on the basis of the requestive directness strategy they included (a separate category; the coding matrix for categories is presented in Table 4). Subsequently, the types of external and internal modification devices accompanying a given head act were listed and coded. They are not the subject of reflection in this paper because they are not separate categories and, as such, cannot be analysed by the statistical method presented here.

The matrix used to classify the requestive strategies present in the interlanguage data collected builds on the existing body of literature on interlanguage and cross-cultural pragmatics. In particular, it combines models of analysis designed by Blum-Kulka et al. (1989b: 1-34, 277-289), 
Table 4. Requestive directness strategies used and their codes in the statistical analysis

\begin{tabular}{|c|c|c|}
\hline $\begin{array}{l}\text { Requestive } \\
\text { directness strategies }\end{array}$ & Code & Example \\
\hline \multicolumn{3}{|r|}{ Direct strategies } \\
\hline $\begin{array}{l}\text { Mood derivable } \\
\text { (imperatives) }\end{array}$ & 1 & Give me some note paper! \\
\hline $\begin{array}{l}\text { Performative } \\
\text { (unhedged) }\end{array}$ & 2 & I am asking you to give me some note paper. \\
\hline $\begin{array}{l}\text { Performative } \\
\text { (hedged) }\end{array}$ & 3 & $\begin{array}{l}\text { I would like/want to ask you to give me some note } \\
\text { paper. }\end{array}$ \\
\hline $\begin{array}{l}\text { Obligation/necessity } \\
\text { statement }\end{array}$ & 4 & $\begin{array}{l}\text { You'll have to/must/should give me some note } \\
\text { paper. }\end{array}$ \\
\hline Want statement & 5 & $\begin{array}{l}\text { I (really) need/want/could do with some note paper } \\
\text { (speaker-oriented). (I really) want/wish you to give } \\
\text { me some note paper. }\end{array}$ \\
\hline $\begin{array}{l}\text { Mitigated want } \\
\text { statement }\end{array}$ & 6 & $\begin{array}{l}\text { I would like/really wish/would prefer you gave me } \\
\text { some note paper; } \\
\text { I would appreciate it if you gave me some note } \\
\text { paper. }\end{array}$ \\
\hline \multicolumn{3}{|r|}{ Indirect strategies } \\
\hline Suggestory formula & 7 & $\begin{array}{l}\text { How about giving me some note paper? (hearer- } \\
\text { oriented) }\end{array}$ \\
\hline $\begin{array}{l}\text { Preparatory } \\
\text { question/query } \\
\text { preparatory/ability } \\
\text { question }\end{array}$ & 8 & Could you give me some note paper (, please)? \\
\hline $\begin{array}{l}\text { Mitigated } \\
\text { preparatory question }\end{array}$ & 9 & $\begin{array}{l}\text { Do you think that you could give me some note } \\
\text { paper? } \\
\text { Would you (mind/be so kind to) give me some note } \\
\text { paper (hearer-oriented willingness question) }\end{array}$ \\
\hline $\begin{array}{l}\text { Mitigated } \\
\text { preparatory } \\
\text { statement }\end{array}$ & 10 & $\begin{array}{l}\text { I was wondering if it is/would be possible for you } \\
\text { to give me some note paper (hearer-oriented) } \\
\text { I don't suppose you can give me some note paper } \\
\text { (hearer-oriented) }\end{array}$ \\
\hline Permission question & 11 & May I take some note paper? \\
\hline \multicolumn{3}{|r|}{ Hints } \\
\hline Strong hint & 12 & I have no note paper on me. \\
\hline
\end{tabular}

Takahashi (2001: 199), Bardovi-Harlig (2001: 14-15), Barron (2003: 350-359), Rue and Qiao (2008: 52-57, 313-314) and Schauer (2009: 89-92) with datadriven amendments (details in Szczepaniak-Kozak, 2018). In particular, some of the requestive directives strategies that appear in the literature do not appear in the corpus collected (e.g., elliptical constructions and availability questions). 
Consequently, the 1,248 requests collected were divided into twelve categories, forming a continuum from the most direct (1) to the most indirect (12) requestive head acts (see Table 4 earlier).

Some measures were taken in order to prevent inaccuracies in the data classification procedure. An inter-rater reliability test was conducted after each data collection with randomly selected data. A random selection of 50 utterances was given to a rater who is a professional applied linguist, and who underwent a training session, including issues regarding the goals of the study and use of the coding scheme. Altogether, more than ten percent (150 utterances) of all data (1,248 in total) underwent such validation. A high degree of agreement was obtained between the two batches which had undergone the inter-rater validation. Since the data comes from a dependent sample and is not interval or ordinal, it was not possible to calculate the Pearson product-moment correlation or Spearman Rank Correlation Coefficients (see Mackey and Gass, 2016: 327-332). For this reason, a qualitative comparison was conducted. Only rarely were the analysis findings different. In the majority of cases, the rater was not able to list all the internal mitigators present in the samples, which are not the subject of analysis in the present paper. In other cases, the data was re-coded where necessary. Additionally, the data underwent numerous regrounding cycles for the purpose of intra-rater reliability checks.

After categorisation of all the requestive forms, the data was coded into numerical values, corresponding to the code of the requestive directness strategy (see Table 4 for coding figures). The data was then fed into $\mathrm{R}$ software (version 3.4.0) for analysis using the model developed by the authors of this paper.

\section{Data analysis: Application of the model}

In what follows, we apply the above-detailed logistic model with multinomial distribution to estimate the probability of success of individual categories (here strategies of requestive directness) in a study conducted over 32 months with a moderately large group $($ maximum $=50$, minimum $=37$ ). The data categories

represent types of pragmatic output operationalised in this study as strategies of 
requestive directness. In our research, we have $k=12$ separate categories into which the requests elicited were classified (see Table 4). The distribution of the strategies across the DCT scenarios is assumed to depend on the values of the six independent variables (see Table 3; a five-variable analysis is presented in Szczepaniak-Kozak, 2018): power distance $(P)$, social distance $(D)$, imposition $(I)$, the speaker's right $(R)$, the hearer's obligation $(O)$, jointly with one more which is assumed to be characteristic of Polish speakers of EFL: the estimation of future social distance $(F)$.

The probability of the individual requestive category (1-12) is estimated independently for each DCP. The estimates of the unknown parameters of the independent variables in the logistic model (cf. Model 1) and the values of the standard deviation error ( $S D$ error) and the $p$-values at the successive data collection points are presented in Table 5 . This table also comprises the estimates of the borders or cut-off points $\boldsymbol{\theta}=\left(\theta_{1}, \theta_{2}, \ldots, \theta_{11}\right)$ between successive categories, because they are necessary to establish the values of the probabilities $\mathbf{p}=\left(p_{1}, p_{2}, \ldots\right.$, $\left.p_{12}\right)^{\mathrm{T}}$. The parameters $\theta_{1}, \theta_{2}, \ldots, \theta_{11}$ are the borders between particular categories. The parameters $\beta_{1}, \beta_{2}, \ldots, \beta_{6}$ which are of interest in this paper are those related to the variables $P, D, I, R, O$ and $F$.

Following the estimates demonstrated in Table 5 and relying on the calculation of the $p$-value, we can claim that, regardless of the data collection point, $P$ and $D$ appear to be highly significant $(p<0.0001$ ). This is in line with the findings of the analysis conducted by Szczepaniak-Kozak (2018) with reference to the five classic parameters of $P, D, I, R$, and $O$. Furthermore, the model justifies not only the existence of the new variable $F$, but also that it is statistically significant $(p<0.0001)$ across the data collection points. Finally, at TDCP, the remaining two variables ( $I$ and $R$ ) become significant as well, assuming the significance level $\alpha=0.05$. All in all, $P, D, F$ influence the probability of selecting a particular requestive directness strategy to the greatest extent.

In real terms, this means that when formulating a request in English, Polish EFL speakers are less eager to take into consideration requestive imposition. This tendency stands in direct contrast to pragmatic output produced by native speakers of English. Szczepaniak-Kozak (2018: 31) explains the lesser attention paid to the 
Table 5. Estimates of the parameters in the logistic model used with variables $P, D, I, R$, $O, F-{ }^{* * *} p<0.001,{ }^{* *} p<0.01,{ }^{*} p<0.05$, AA - no response of this type provided

\begin{tabular}{llllllllllllc}
\hline \multicolumn{1}{l}{ FDCP } & \multicolumn{1}{l}{ SDCP } & \multicolumn{7}{c}{ TDCP } \\
\hline Par. & $\begin{array}{l}\text { Esti- } \\
\text { mate }\end{array}$ & $\begin{array}{l}S D \\
\text { error }\end{array}$ & $\begin{array}{c}P \\
\text { value }\end{array}$ & Par. & $\begin{array}{l}\text { Esti- } \\
\text { mate }\end{array}$ & $\begin{array}{l}S D \\
\text { error }\end{array}$ & $\begin{array}{c}P \\
\text { value }\end{array}$ & Par. & $\begin{array}{l}\text { Esti- } \\
\text { mate }\end{array}$ & $\begin{array}{l}S D \\
\text { error }\end{array}$ & $\begin{array}{c}P \\
\text { value }\end{array}$ \\
\hline$\Theta_{1}$ & -4.52 & 0.71 & - & $\Theta_{1}$ & -5.85 & 0.86 & - & $\Theta_{1}$ & -7.52 & 0.91 & - \\
\hline$\Theta_{2}$ & -4.50 & 0.71 & - & $\Theta_{2}$ & AA & AA & - & $\Theta_{2}$ & -7.46 & 0.91 & - \\
\hline$\Theta_{3}$ & -4.22 & 0.70 & - & $\Theta_{3}$ & -5.31 & 0.84 & - & $\Theta_{3}$ & -7.08 & 0.89 & - \\
\hline$\Theta_{4}$ & -4.07 & 0.70 & - & $\Theta_{4}$ & -5.29 & 0.84 & - & $\Theta_{4}$ & -7.01 & 0.89 & - \\
\hline$\Theta_{5}$ & -3.76 & 0.69 & - & $\Theta_{5}$ & -5.16 & 0.83 & - & $\Theta_{5}$ & -6.81 & 0.88 & - \\
\hline$\Theta_{6}$ & -3.51 & 0.68 & - & $\Theta_{6}$ & -4.89 & 0.83 & - & $\Theta_{6}$ & -6.64 & 0.87 & - \\
\hline$\Theta_{7}$ & -3.26 & 0.68 & - & $\Theta_{7}$ & -4.71 & 0.82 & - & $\Theta_{7}$ & -6.42 & 0.87 & - \\
\hline$\Theta_{8}$ & -0.80 & 0.67 & - & $\Theta_{8}$ & -2.15 & 0.81 & - & $\Theta_{8}$ & -4.15 & 0.85 & - \\
\hline$\Theta_{9}$ & -0.39 & 0.68 & - & $\Theta_{9}$ & -1.55 & 0.82 & - & $\Theta_{9}$ & -3.55 & 0.85 & - \\
\hline$\Theta_{10}$ & -0.20 & 0.68 & - & $\Theta_{10}$ & -1.35 & 0.82 & - & $\Theta_{10}$ & -3.32 & 0.86 & - \\
\hline$\Theta_{11}$ & 1.29 & 0.71 & - & $\Theta_{11}$ & 0.25 & 0.87 & - & $\Theta_{11}$ & -2.16 & 0.88 & - \\
\hline $\mathrm{P}$ & -0.75 & 0.15 & $<0.001$ & $\mathrm{P}$ & -1.10 & 0.18 & $<0.001$ & $\mathrm{P}$ & -1.27 & 0.18 & $<0.001$ \\
\hline $\mathrm{D}$ & 1.48 & 0.23 & $<0.001$ & $\mathrm{D}$ & 1.78 & 0.26 & $<0.001$ & $\mathrm{D}$ & 1.84 & 0.27 & $<0.001$ \\
\hline $\mathrm{I}$ & 0.07 & 0.16 & 0.681 & $\mathrm{I}$ & -0.01 & 0.19 & 0.946 & $\mathrm{I}$ & -0.38 & 0.19 & 0.045 \\
\hline $\mathrm{R}$ & -0.54 & 0.38 & 0.153 & $\mathrm{R}$ & -0.56 & 0.42 & 0.185 & $\mathrm{R}$ & 0.37 & 0.43 & 0.398 \\
\hline $\mathrm{O}$ & 0.28 & 0.42 & 0.512 & $\mathrm{O}$ & 0.057 & 0.48 & 0.905 & $\mathrm{O}$ & -1.23 & 0.50 & 0.013 \\
\hline $\mathrm{F}$ & -1.24 & 0.25 & $<0.001$ & $\mathrm{~F}$ & -1.50 & 0.27 & $<0.001$ & $\mathrm{~F}$ & -1.56 & 0.28 & $<0.001$ \\
\hline & & & & & & & & & & & \\
\hline
\end{tabular}

conditioning force of imposition among Poles speaking EFL by the notions of deference and solidarity. She suggests that in Anglophone culture politeness is associated with non-imposition, which translates into indirectness or deference, whereas Polish culture is oriented towards positive politeness, and the related importance of in-group membership and solidarity, which translates into a greater degree of directness of requests, and avoidance of distancing oneself from the hearer and the speech act.

Furthermore, on the basis of the estimates displayed in Table 5, probabilities of the individual categories of requestive strategies were aggregated. Figures 1-4 present the probabilities calculated for the four most frequent and probable directness strategies (that is, the individual categories in the analysis) in the corpus collected (see Table 4). The findings of the probability analysis are briefly commented on in what follows. 
The results of the data modelling suggest that the probability of use with reference to Strategy 1 (mood derivable) increases moderately for Scenario 3, and less so for Scenarios 1, 4, and 8 over the examined period (cf. Figure 1). This means that the statistical model proves that the use of Strategy 1 in the corpus is high. More importantly, the model predicts its moderate probability of use in other contexts for which we do not have data. Hence the logistic model not only draws conclusions concerning the existing data, but also predicts uses in other contexts.

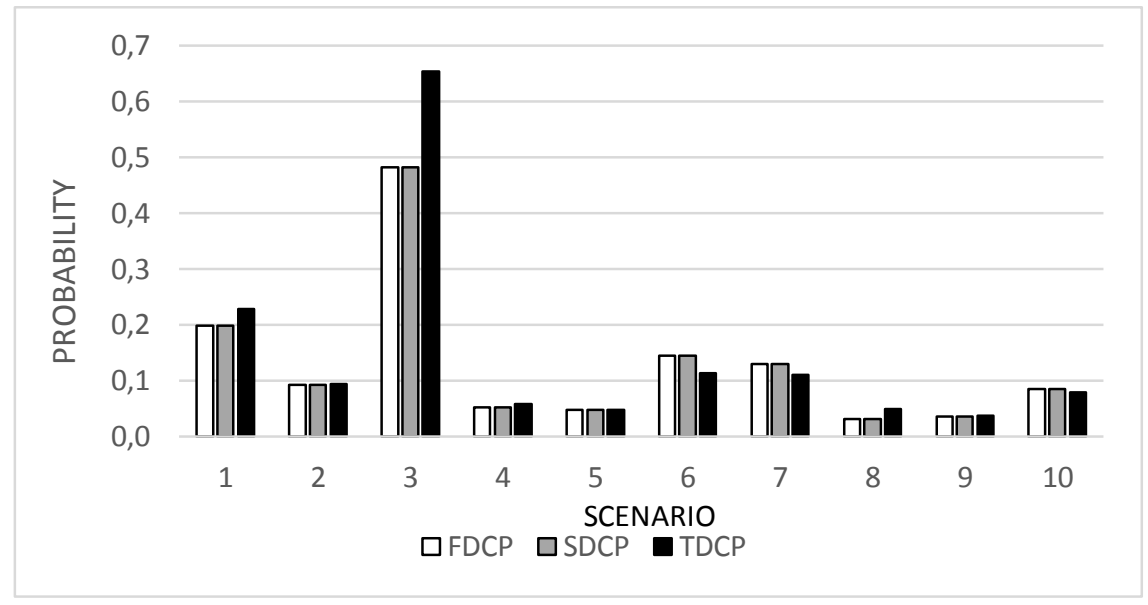

Figure 1. Probability of use of Strategy $1 *$ DCP and Scenario

With reference to Strategy 8 (preparatory question), the probability is the highest of all the requestive directness strategies which appear in the corpus, but we can observe a slight decrease in the probability value for Scenarios 3, 5, and 9 across the data collection points (cf. Figure 2). Notably, at this stage of their ILP, the cohort use the preparatory query in situations, such as Scenario 6, which require a more direct strategy, e.g., mood derivable. This might imply that, on average, they are not able to select the appropriate strategy for a particular situation, but rather prefer one strategy to others and apply it across all scenarios. This enables us to posit that Polish learners of EFL overgeneralise this strategy as an all-purpose one, thus reducing the burden of matching particular sociopragmatic settings with an appropriate pragmalinguistic feature, and, perhaps, their cognitive control effort. 


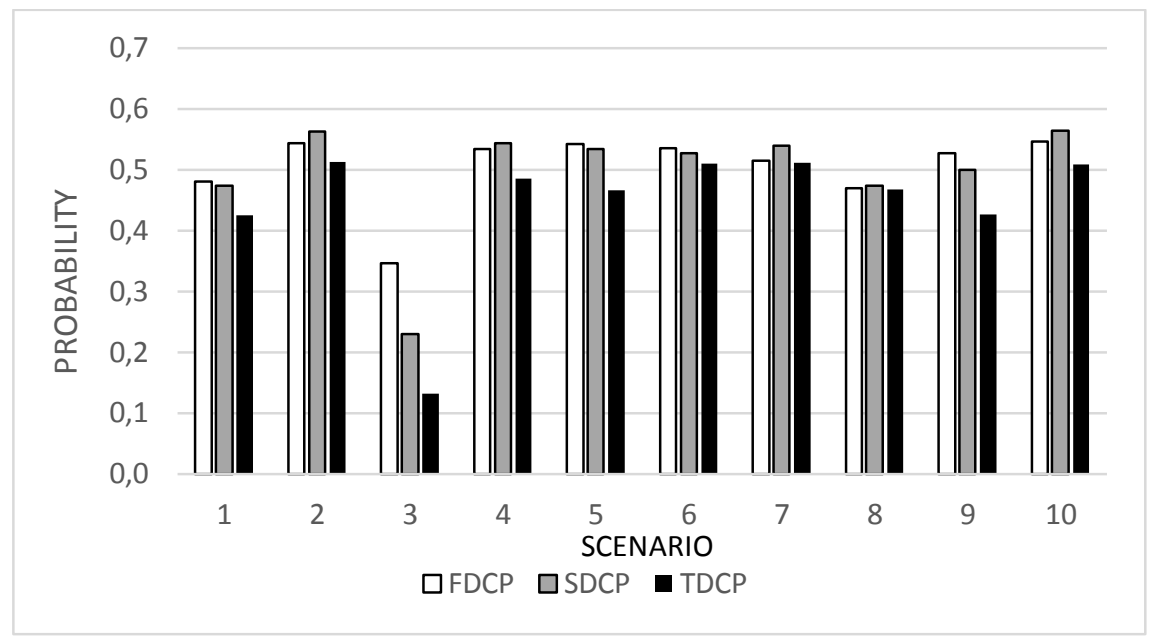

Figure 2. Probability of use of Strategy $8 *$ DCP and Scenario

With reference to Strategy 9 (mitigated preparatory question), there is a noticeable increase in the probability of its use, though relatively small (cf. Figure 3). An especially welcome development is the increase in the probability value for almost all the scenarios analysed in the longitudinal perspective, except for Scenario 3, which is a consequence of the fact that this scenario features an increasing probability value for Strategy 1 (cf. Figure 1).

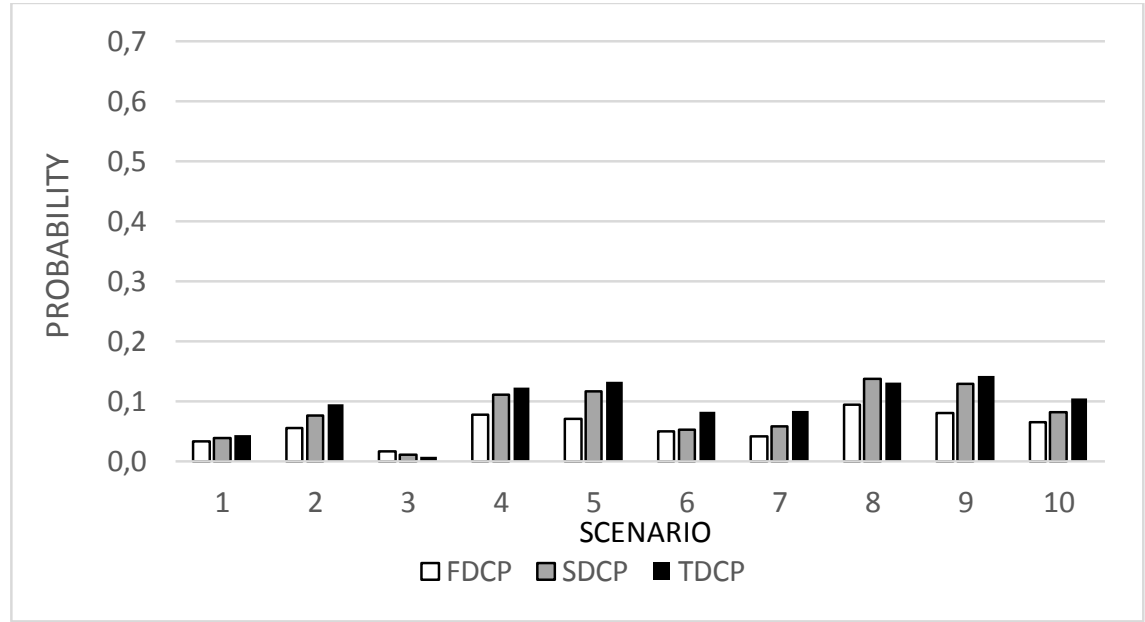

Figure 3. Probability of use of Strategy $9 *$ DCP and Scenario 
As is shown in Figure 4, fairly stable but low probability values are characteristic of Strategy 11 (permission question) across the data collection points, with a slight increase in the case of Scenarios 5 and 9. In fact, these two scenarios produce the most pronounced shift towards the more indirect continuum of requestive directness.



Figure 4. Probability of use of Strategy $11 *$ DCP and Scenario

Furthermore, a year-to-year analysis was conducted by means of the logistic model. The data collection point was treated as a factor determining which directness strategy (out of 12 categories) was preferred by the cohort in general. The analysis indicates that the data collection points do not constitute a decisive factor in the requestive strategy choice - the correlations are generally low for each point. The $p$-values calculated for each combination of DCTs were greater than 0.05:

- $p$-value for the comparison of FDCP and SDCP $=0.861$ (statistically insignificant),

- $p$-value for FDCP and TDCP $=0.572$ (statistically insignificant),

- $p$-value for SDCP and TDCP $=0.487$ (statistically insignificant).

These coefficients also allow us to suggest that FDCP and SDCP give similar probability values, i.e., are very similar in the patterns of strategy choice, whereas 
there is a slight increase in the significance value calculated for TDCP. In this sense, at TDCP the size of the change is more significant, in contrast to the significance figures for FDCP and SDCP. However, it should be noted that, in general, there is no statistically significant difference between the particular DCPs in terms of choices of requestive directness strategy.

\section{Discussion of the results, limitations of the study and implications for future research}

The present study has demonstrated several important points concerning the analysis of ILP data. Primarily, its findings verified the usefulness of the multinomial logistic model (Model 1) for statistical processing of longitudinal data. In contrast to ANOVA or the $t$-test, this statistical model allows not only the tracking of changes in the pragmatic output of EFL learners, but primarily it enables the drawing of conclusions on the dependence between the probability (success) of particular analytical categories and the values of independent variables (in our case parameters of context). Another definite merit is that primary data is subjected to processing in the model. Furthermore, a considerable advantage of the logistic model is that it allows the interpretation of $\exp \left(\beta_{\mathrm{i}}\right)$ parameters. To this aim, the notion of odds is applied, defined as the quotient of the probability of the event occurring and the probability of non-occurrence of the event. In the model under consideration (Model 1), odds can be specified as a function of the explanatory independent variables:

$$
\frac{\gamma_{j}}{1-\gamma_{j}}=\exp \left(\theta_{j}+\sum_{i=1}^{p} \beta_{i} x_{i}\right)
$$

In the case of a given word, $\exp \left(\theta_{\mathrm{j}}\right)$ is interpreted as the probability that the phenomenon will occur in the reference group.

The analysis relying on the logistic model enabled us to determine the interaction between contextual factors, operationalised as independent variables in our study, and the pragmatic output collected. Firstly, we were able to indicate the extent to which a given independent variable conditions the use of requestive directness strategies by Poles learning EFL. It appears that, regardless of the data 
collection point, $P$ (power distance) and $D$ (social distance) have a highly significant influence on the use of requestive directness strategies by Poles learning EFL. The same can be said about the sixth variable $(F)$, which Szczepaniak-Kozak (2018) proposes as one which characterises the pragmatic output of Poles in English. We were able to prove that the estimation of future social distance $(F)$ considerably influences the choice of pragmatic realisations in particular scenarios and at successive data collection points. Furthermore, based on the estimation of the parameters (independent variables in our case), which are presented in Table 5, we can estimate the probability of use of a particular response (in our study a requestive directness strategy) by language learners depending on the scenario. This model also allows the prediction of changes in the probability figures for scenarios which are not included in the DCT used in our study. In other words, it can provide a profile of language use in a scenario which features values of the independent variables different from those which we have investigated, that is, other non-examined scenarios.

It is important to note that, despite its significance for ILP and PC research, this study has several limitations. First of all, the model cannot be used when the units observed, e.g., internal or external mitigators, are non-exclusive categories. Such data can be analysed only by means of descriptive statistics. Secondly, given the complexity of the model, the number of participants could usefully be larger, as this would help "to reduce the bias in estimating parameters" (Matsumura, 2001: 669). The same applies to the inter-rater testing used in our study. There was only one expert linguist invited to conduct additional ratings of selected requests. Although the results of such comparisons are quite reliable and the data used is very robust because of the study design, we realise that individual differences are possible among expert ratings. In order to overcome this problem in further research on the proposed statistical methodology, five to six raters should ideally be used to ensure consistency of ratings and judgments. Finally, and perhaps most importantly, the sixth independent variable under test in this paper is characteristic of Poles, due to their tendency to transfer certain sociopragmatic evaluations into the target language. More studies are necessary to test whether this independent variable conditions the pragmatic output or 
comprehension of other pragmatic features by Poles learning English. Testing interlanguage data elicited from other national groups learning English could also yield useful results in this regard. Our explanation of this tendency is tentative and requires further exploratory research by means of, for instance, think-aloud protocols. However, the fact that $F$ might be a sociopragmatic transfer from Polish does not negate the merits of the statistical model tested in this paper. Szczepaniak-Kozak (2018) used the same multinomial logistic model to estimate probability with reference to five classic independent variables $(P, D, I, R$ and $O)$ in wide use in ILP studies, and her analysis revealed differences in the degree to which they influenced the dependent variables.

Despite these limitations, the results of the analysis included in this paper demonstrate the usefulness of the multinomial logistic model for investigating the scale of change in pragmatic output and unknown probability of use in longitudinal research into interlanguage pragmatics.

\section{REFERENCES}

Agresti A. (1984): Analysis of ordinal categorical data. Wiley, New York.

Alcón-Soler E. (2015): Pragmatic learning and study abroad: Effects of instruction and length of stay. System 48: 62-74.

Bakinowska E. (2004). Analyzing experiments by generalised linear models. Biometrical Letters 41(2): 37-49

Barron A. (2000): Acquiring 'different strokes': A longitudinal study of the development of L2 pragmatic competence. German as a Foreign Language 2: 1-30.

Barron A. (2003): Acquisition in interlanguage pragmatics. Learning how to do things with words in a study abroad context. John Benjamins, Amsterdam.

Blum-Kulka S. (1987). Indirectness and politeness in requests: Same or different. J. of Pragmatics 11: 131-146.

Blum-Kulka S., House J., Kasper G. (eds.) (1989): Cross-cultural pragmatics: Requests and apologies. Ablex, Norwood, NJ.

Brown P., Levinson S. (1987): Politeness: Some universals in language use. Cambridge University Press, Cambridge.

Decoo W. (1996): The induction-deduction opposition: Ambiguities and complexities of the didactic reality. Int. Rev. of Applied Linguistics in Lg. Teaching 34: 95-118.

Fraser B. (1990): Perspectives on politeness. J. of Pragmatics 14(2): 219-236.

Ghavamnia M., Tavakoli M., Rezazadeh M. (2011): A comparative study of requests among L2 English, L1 Persian, and L1 English speakers. Revista Electrónica de Lingǘstica Aplicada 10: 105-123. 
Glaser K. (2014): Inductive or deductive? The impact of method of instruction on the acquisition of pragmatic competence in EFL. Cambridge Scholars Publishing, Newcastle upon Tyne.

Gomez-Laich M.P. (2016): Second language learners' divergence from target language pragmatic norms. Studies in 2nd LG. Learning and Teaching 6(2): 249-269.

Hudson T. (2001): Indicators for pragmatic instruction: Some quantitative tools. In Rose K.R., Kasper G. (eds.), Pragmatics in language teaching, 283-300. Cambridge University Press, Cambridge.

Hudson T., Detmer E., Brown J.D. (1995): Developing prototypic measures of crosscultural pragmatics. Second Language Teaching and Curriculum Center, University of Hawai'i, Manoa, HI.

Jaworski A. (1994): Pragmatic failure in a second language: Greeting responses in English by Polish students. IRAL 1: 41-55.

Kim Y., Taguchi N. (2015): Promoting task-based pragmatics instruction in EFL classroom contexts: The role of task complexity. The Modern Lg. J. 99(4): 656-677.

Lewandowska-Tomaszczyk B. (1989): Praising and complimenting. In Oleksy W. (ed.), Contrastive pragmatics, 73-100. Benjamins, Amsterdam.

Li Q. (2016): Variations in developmental patterns across pragmatic features. Studies in 2nd Lg. Learning and Teaching 6(4): 587-617.

Li S. (2014): The effects of different levels of linguistic proficiency on the development of L2 Chinese request production during study abroad. System 45: 103-116.

Liu J. (2006): Measuring interlanguage pragmatic knowledge of EFL learners. Peter Lang, Frankfurt am Main.

Liu J. (2007): Development of a pragmatics test for Chinese EFL learners. Lg. Testing 24 (3): 391-415.

Mackey A., Gass S.M. (2016): Second language research methodology and design (2nd ed.). Rutledge, New York.

Martínez-Flor A., Usó-Juan E. (2006): Learners' use of request modifiers across two university ESP disciplines. Ibérica 12: 23-42.

Matsumura S. (2001): Learning the rules for offering advice: A quantitative approach to second language socialization. Lg. Learning 51: 635-679.

McCullagh P., Nelder J.A. (1989): Generalised linear models. Chapman and Hall, London.

McCulloch Ch., Searle S.R. (2001): Generalised, linear, and mixed models. Wiley, New York.

Ogiermann E., Saßenroth D. (2012): Statistics in contrastive pragmatics. In Ruiz de Zarobe L., Ruiz de Zarobe Y. (eds.), Speech acts and politeness across languages and cultures, 369-398. Peter Lang., Bern.

R: A language and environment for statistical computing (Version 3.4.0) by R Core Team (2017). R Foundation for Statistical Computing, Vienna, Austria. URL https://www.R-project.org/

Rue Y.-J., Zhang Qiao G. (2008): Request strategies: A comparative study in Mandarin Chinese and Korean. John Benjamins, Amsterdam.

Scarcella R.C. (1983): Discourse accent in second language performance. In Gass S., Selinker L. (eds.), Language transfer in language learning, 306-326. Newbury House, Rowley, MA. 
Scarcella R.C. (1992): Interethnic conversation and second language acquisition: Discourse accent revisited. In Gass S., Selinker L. (eds.), Language transfer in language learning, 109-137. John Benjamins, Amsterdam.

Schauer G. (2009): Interlanguage pragmatics development: The study abroad context. Continuum, London.

Schenker Th. (2016): Syntactic complexity in a cross-cultural e-mail exchange. System 63, (December): 40-50.

Szczepaniak-Kozak A. (2018): Interlanguage pragmatic competence: A longitudinal study of 'pragmatic accent' in learning EFL. Wydawnictwo UAM, Poznań.

Taguchi N. (2007): Development of speed and accuracy in pragmatic comprehension in English as a foreign language. TESOL Quarterly 41(2): 313-338.

Taguchi N. (2008): Cognition, language contact, and the development of pragmatic comprehension in a study-abroad context. Lg. learning 58 (1): 33-71.

Taguchi N. (2010): Longitudinal studies in interlanguage pragmatics. In Trosborg A. (ed.), Handbook of pragmatics, vol. 7, 333-361. Mouton de Gruyter, Berlin.

Taguchi N. (2011): Pragmatic development as a dynamic, complex process: General patterns and case histories. The Modern Lg. J. 95 (4): 605-627.

Takahashi S. (2001): Input enhancement in developing pragmatic competence. In Rose K.R., Kasper G. (eds.), Pragmatics in language teaching, 171-199. Cambridge University Press, Cambridge.

Takahashi S. (2015): The effects of learner profiles on pragmalinguistic awareness and learning. System 48 (February): 48-61.

Thomas J. (1995): Meaning in interaction. An introduction to pragmatics. Longman, London. 9 